\title{
Extending harmonized national forest inventory herb layer vegetation cover observations to derive comprehensive biomass estimates
}

\author{
Markus Didion
}

\begin{abstract}
Background: National forest inventories (NFI) have a long history providing data to obtain nationally representative and accurate estimates of growing stock. Today, in most NFIs additional data are collected to provide information on a range of forest ecosystem functions such as biodiversity, habitat, nutrient and carbon dynamics. An important driver of nutrient and $\mathrm{C}$ cycling is decomposing biomass produced by forest vegetation. Several studies have demonstrated that understory vegetation, particularly annual plant litter of the herb layer can contribute significantly to nutrient and C cycling in forests. A methodology to obtain comprehensive, consistent and nationally representative estimates of herb layer biomass on NFI plots could provide added value to NFIs by complementing the existing strong basis of biomass estimates of the tree and tall shrub layer. The study was based on data from the Swiss NFI since it covers a large environmental gradient, which extends its applicability to other NFIs.
\end{abstract}

Results: Based on data from 405 measurements in nine forest strata, a parsimonious model formulation was identified to predict total and non-ligneous herb layer biomass. Besides herb layer cover, elevation was the main statistically significant explanatory variable for biomass. The regression models accurately predicted biomass based on absolute percentage cover (for total biomass: $R^{2}=0.65, p=0$; for non-ligneous biomass: $\left.R^{2}=0.76 ; p=0\right)$ as well as on cover classes $\left(R^{2}=0.83 ; p=0\right.$; and $\left.R^{2}=0.79, p=0\right)$, which are typically used in NFIs. The good performance was supported by the verification with data from repeated samples. For the 2 nd, 3rd, and 4th Swiss NFI estimates of non-ligneous above-ground herb layer biomass 586.6 $\pm 7.7,575.2 \pm 7.6$, and $586.7 \pm 7.9 \mathrm{~kg} \cdot \mathrm{ha}^{-1}$, respectively.

Conclusions: The study presents a methodology to obtain herb layer biomass estimates based on a harmonized and standardized attribute available in many NFIs. The result of this study was a parsimonious model requiring only elevation data of sample plots in addition to NFI cover estimates to provide unbiased estimates at the national scale. These qualities are particularly important as they ensure accurate, consistent, and comparable results.

Keywords: Model, ENFIN, Switzerland, Ground layer, Herbs, Ferns, Grasses, Shrubs, Carbon, Litter

Correspondence: markus.didion@wsl.ch

Forest Resources and Management, Swiss Federal Research Institute WSL,

Zürcherstrasse 111, 8903 Birmensdorf, Switzerland

๑ The Author(s). 2020 Open Access This article is licensed under a Creative Commons Attribution 4.0 International License, which permits use, sharing, adaptation, distribution and reproduction in any medium or format, as long as you give appropriate credit to the original author(s) and the source, provide a link to the Creative Commons licence, and indicate if changes were made. The images or other third party material in this article are included in the article's Creative Commons licence, unless indicated otherwise in a credit line to the material. If material is not included in the article's Creative Commons licence and your intended use is not permitted by statutory regulation or exceeds the permitted use, you will need to obtain permission directly from the copyright holder. To view a copy of this licence, visit http://creativecommons.org/licenses/by/4.0/. 


\section{Background}

Programs to monitor natural resources provide important data for improving the understanding and the management of complex ecological systems (Davis 1993). Among such programs, national forest inventories (NFI) have a long history (McRoberts et al. 2010). Historically, forest inventories focused on timber resources and the accurate estimation of growing stock. Today, in most NFIs additional data are collected to provide information on a range of forest ecosystem functions such as biodiversity, habitat, nutrient and carbon dynamics (Tomppo et al. 2010). An important driver of nutrient and $\mathrm{C}$ cycling is decomposing biomass produced by the forest vegetation. In temperate forest ecosystems, studies to estimate the amount of biomass production have typically focused on overstory plants (Landuyt et al. 2019a), which is the highest vegetation stratum typically dominated by woody species of the tree strata. However, several studies have demonstrated that understory vegetation including bryophytes, herbaceous and woody species growing on the forest floor, particularly annual plant litter of the herb layer can contribute significantly to nutrient and C cycling in forests (e.g., Gilliam 2007; Kumar et al. 2018; Landuyt et al. 2019a). A methodology to estimate herb layer biomass on NFI plots could provide added value to NFIs by complementing the existing strong basis of biomass estimates of the tree and tall shrub layer (Alberdi et al. 2010; Alberdi et al. 2018).

Following the definition of the herb layer (sometimes also ground or field layer) suggested by the European National Forest Inventory Network (ENFIN), it comprises all non-ligneous and ligneous plants $<0.5 \mathrm{~m}$ and may include shrubs, herbs, and ferns (cf. Appendix Working Group 3 Definitions in Tomppo et al. 2010), i.e. it represents an estimate of the total cover of the herb layer over all species groups. Total herb layer (THL) cover is estimated in many NFIs (Tomppo et al. 2010; Chirici et al. 2011) and methods exist to estimate plant biomass based on their cover (e.g. Muukkonen and Mäkipää 2006; Muukkonen et al. 2006; Welch et al. 2007; Schulze et al. 2009; Heinrichs et al. 2010). However, these methods require cover estimates of individual morphological groups and height estimates (e.g. PhytoCalc; Schulze et al. 2009; Heinrichs et al. 2010), or are not comprehensive of the THL and are representative of specific forest types only (e.g. Muukkonen and Mäkipää 2006; Muukkonen et al. 2006; Welch et al. 2007). Following the ENFIN definition of the herb layer, it presents an aggregate of the entire layer and hence estimates for individual morphological groups are typically not available limiting the application of methods that require such additional data. To utilize aggregated THL cover estimates in NFIs for biomass estimation, a methodology is required that is consistent with the holistic ENFIN herb layer definition and is representative at the national scale. A number of NFIs apply the ENFIN methodology, or collect data than can be transferred into this stratification (Alberdi et al. 2010; Tomppo et al. 2010).

In the Swiss NFI, THL cover is estimated on each sample plot since the second inventory (1994-1996) consistent with the ENFIN herb layer definition. Due to varied Swiss topography, the NFI sample plots cover a large environmental gradient providing an excellent opportunity to develop a methodology that could be used in other NFIs. On all sample plots of the Swiss NFI, THL cover including herbs, grasses and sedges, ferns, and dwarf shrubs is recorded in six percentage cover classes. The THL cover estimate thus accounts for all plants excluding mosses, lichens, large perennial woody shrubs > ca. $50 \mathrm{~cm}$, and young trees.

The objective of this study was to develop a model for predicting THL biomass from the cover estimated following the ENFIN definition. With the aim to produce biomass estimates that are nationally representative, the study extents on previous models (e.g. Muukkonen and Mäkipää 2006; Muukkonen et al. 2006; Welch et al. 2007; Schulze et al. 2009; Heinrichs et al. 2010) as it relates to a standardized attribute that is commonly estimated in NFIs. In addition to a total cover to total biomass model, models for individual plant groups were developed, which allows an adaptation to countryspecific definitions of the herb layer.

In order to achieve the study objective and aim, destructive sampling of plant biomass along with plant cover estimates following the NFI methodology were required. Based on studies demonstrating good correlations between herb layer biomass and stand characteristics (e.g. Landuyt et al. 2019b), we analyzed data from the three Swiss NFIs with observations for THL cover to identify a suitable sampling design. Since potential explaining site attributes such as elevation, forest type, dominant tree species, tree basal area, etc. returned only weak or no correlation to herb layer cover, three cluster regions representative of the climatic gradient between eastern, western, and southern Switzerland were created. The clusters were further stratified into three elevation classes and within each class and 15 sites were selected based on a balanced design to evenly represent each herb layer cover class. Experienced members of the NFI field crew collected the necessary data on a total of $4051 \mathrm{~m} \times 1$ m sample plots from 135 study sites. Biomass estimates should be representative of 'peak biomass' to ensure consistency between observations of plots visited at different dates, and to capture the full extent of biomass production (cf. Landuyt et al. 2019a). Since in a regular NFI field season it is not possible to visit all plots at the time of peakbiomass, field crews are instructed to account for the any differences between the observed conditions and the 
conditions at time of peak biomass. To examine the accuracy of the estimates, biomass was repeatedly estimated on a subsample of sites between April and late-September 2017. Since small shrubs are considered part of the herb layer, shrub biomass was separated into ligneous (woody stem) and non-ligneous (leaves) components to more accurately estimate annual THL biomass production. Additionally, C and $\mathrm{N}$ contents of biomass samples were analyzed to obtain additional information applicable for, for example, estimating the $\mathrm{C}$ balance of forests or $\mathrm{N}$ dynamics (de Wit et al. 2006; Landuyt et al. 2019a).

\section{Methods}

\section{Sites}

The goal was to cover the range of forests regarding type and growing stock in the five regional forest strata of the NFI (production regions; Brändli and Hägeli 2019) as well as the 15 strata used in the Swiss greenhouse gas inventory, i.e. three additional elevation classes in each of the five NFI regions (chp. 6.4.2.2 in FOEN 2019). To this end, three cluster regions (North-East, North-West, South) representing the main environmental gradients in Switzerland were identified and stratified by three elevation classes $(\leq 600,601-1200,>1200 \mathrm{~m}$ a.s.l.) based on prior information from permanent NFI sample plots on forest type and THL cover class. In each of the resulting nine strata, 15 study sites were installed to represent five THL cover classes $\geq 1 \%$ cover (Table 1 ) with three replicates each to capture the variability caused by forest stand structure and climate. Thus, there were 45 sites in each cluster region and also 45 sites within each elevation class with a total of 135 study sites (Fig. 1). On each site, data on THL cover and above-ground biomass (henceforth biomass) were collected on. Since destructive sampling is not allowed on regular NFI plots, a 50 $\mathrm{m} \times 50 \mathrm{~m}$ reference plot was established at each site. The reference plots were established following the NFI protocol (NFI Field manual; Düggelin and Keller 2017). As independent or explanatory variables which are available for all NFI sample plots, we collected for each reference plot information on elevation, dominant tree species, forest type, successional stage, cover of tree regeneration, and cover of the shrub layer (i.e. all woody plants between ca. 0.5 and $3 \mathrm{~m}$ in height as well as the lower branches of larger trees). It was ensured to cover a representative gradient for each attribute (Tables $\mathrm{S} 1-1$ to S1-5). The distribution of study sites with elevation classes varied because of topography and the presence of suitable forests within a cluster region (Fig. S1-1).

Study sites below $600 \mathrm{~m}$ elevation were visited between 17 May and 10 June 2017, sites between 601 and $1200 \mathrm{~m}$ in the time of 18 July and 12 August 2017, and the sites above $1200 \mathrm{~m}$ between 5 and 23 September 2017. The temporal staggering was to ensure to capture the biomass peak of the vegetation at the different elevation levels.

In each cluster region, three study sites below $600 \mathrm{~m}$ were revisited during the second and third field campaigns (suppl. Material S2) to i) evaluate the consistency of the cover observations regarding seasonal variation, and ii) to obtain additional independent cover and biomass data for model verification. Evaluating consistency of observations over time was particularly important because the model is to be used to estimate biomass on regular NFI sample plots which are visited typically between April and October.

\section{Herb layer cover estimation in the Swiss NFI}

The NFI attribute "herb layer cover" is defined consistent with the recommended ENFIN definition (cf. Appendix - Working Group 3 Definitions in Tomppo et al. 2010 ) as the percentage cover in six classes (Table 1) within the $50 \mathrm{~m}$ by $50 \mathrm{~m}$ reference plot including ferns, grasses, sedges, herbs, and dwarf shrubs but not mosses and lichens (Düggelin and Keller 2017); specifically excluded are climbing (e.g. Hedera and Clematis spp.) and creeping plants (e.g. Pinus mugo) and large perennial woody shrubs (e.g. Frangula alnus, Corylus, Cornus, Lonicera spp). Cover is observed on each NFI sample plot

Table 1 Total herb layer (THL) cover classes in the Swiss National Forest Inventory (NFI) and in this study. The column frequency presents the number of occurrences of a cover class on the 405 subplots. The column frequency - non-woody presents the number of subplots with measured woody and non-woody shrub biomass or without shrub occurrence within a cover class. The column mean cover subplot present cover data for 405 subplots. The column mean cover reference plot present cover data for 135 reference plots with 27 plots within each cover class

\begin{tabular}{lllllll}
\hline NFI THL Cover class & $\begin{array}{l}\text { NFI Definition } \\
\text { (THL cover, \%) }\end{array}$ & This study & Frequency & $\begin{array}{l}\text { Frequency - } \\
\text { non-woody }\end{array}$ & $\begin{array}{l}\text { Mean cover } \\
\text { subplot (\% } \pm \text { SD) }\end{array}$ & $\begin{array}{l}\text { Mean cover reference } \\
\text { lot (\% SD) }\end{array}$ \\
\hline 1 & $<1$ & No & na & na & na & na \\
2 & $1-9$ & Yes & 76 & 62 & $5.6 \pm 2.2(76)$ & $6.6 \pm 1.7(27)$ \\
3 & Yes & 92 & 64 & $17.2 \pm 5.4(92)$ & $18.2 \pm 4.1(27)$ \\
4 & $10-25$ & Yes & 81 & 55 & $39.3 \pm 7.8(81)$ & $38.4 \pm 5.3(27)$ \\
5 & $26-50$ & Yes & 75 & 42 & $64.5 \pm 7.2(75)$ & $64.4 \pm 4.5(27)$ \\
6 & $51-75$ & Yes & 81 & 32 & $92.9 \pm 6.4(81)$ & $90.4 \pm 7.7(27)$ \\
\hline
\end{tabular}




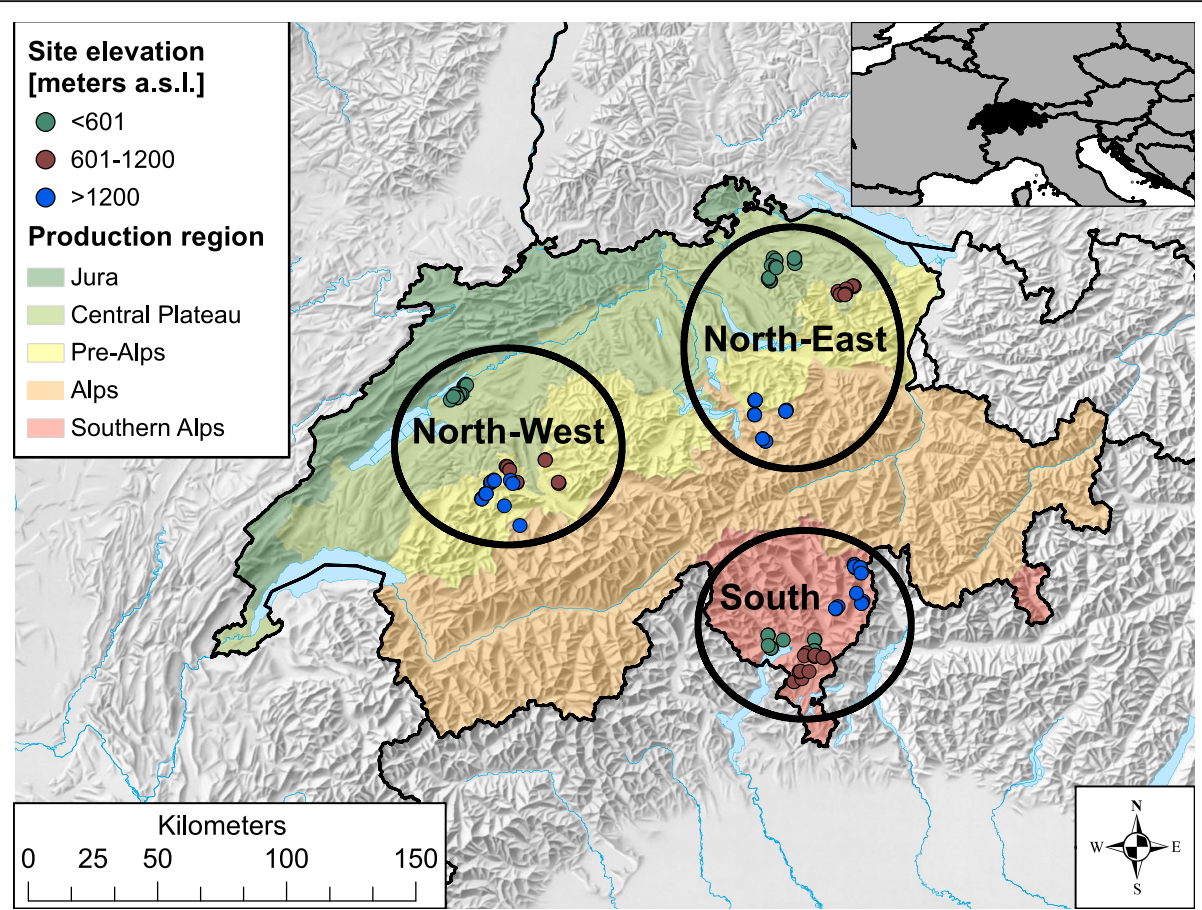

Fig. 1 Location of the 135 study sites in 9 strata (3 elevation classes in 3 cluster regions) within the $5 \mathrm{NFI}$ production regions

and is estimated from the center of the reference plot following six cover classes. The herb layer cover attribute was first included in the NFI2 which was carried out between 1993 and 1995 and estimates were repeated in the NFI3 (2004-2006) and NFI4 (2009-2017). Field crews are trained to ensure consistency in the cover estimates regarding seasonal variation in the species composition and in the biomass development.

In this study we restricted the sampling to cover classes with $\geq 1 \%$ vegetation cover (i.e. classes 2 to 6 in Table 1). Cover was estimated as percentage on a continuous scale resulting in more accurate and precise estimates than wider cover classes. The more accurate and precise estimates can be used to evaluate the accuracy of the relationship between the less detailed cover class and biomass. Additionally to the standard NFI methodology which considers the herb layer as a whole, the relative contribution of individual plant groups (small and tall herbs, grasses, sedges, ferns, dwarf shrubs; Table S3-1) to the THL cover was evaluated based on the plant group percentage cover estimates.

\section{Vegetation sampling and processing}

To develop a model for estimating the biomass of each plant group in the herb layer and for the whole herb layer, on each of the 135 study sites (15 sites in 9 strata), 3 subplots of $1 \mathrm{~m} \times 1 \mathrm{~m}$ were established in three directions (azimuth $0^{\circ}, 150^{\circ}$, and $266^{\circ}$ ) at $12.5 \mathrm{~m}$ distance from the center of the $50 \mathrm{~m} \times 50 \mathrm{~m}$ reference plot (Fig. S4-1). On each of the 405 subplots (135 sites with 3 subplots) the total cover of all THL plants and the relative percentage cover of each present plant group consistent with the procedure for the reference plot was estimated (for data see Didion et al. 2018). To be able to use the cover estimates as predictors for plant biomass, biomass within the $1 \mathrm{~m} \times$ $1 \mathrm{~m}$ quadrat (Fig. S4-2) was removed separately by plant group. Because biomass on subplots on sites that were revisited was removed during the first visit, subplots in the second and third visit were offset at the corners of the subplots that were established in the previous visits.

After biomass removal, a hanging scale (precision $5 \mathrm{~g}$ ) was used to measure fresh weight separately for each plant group. At the laboratory the plant material was dried for $48 \mathrm{~h}$ at $65^{\circ} \mathrm{C}$, or until the weight remained constant (for data see Didion et al. 2018). After drying, shrub biomass from a subsample $(N=68)$ of all subplots with shrub cover $(N=218)$ was separated into leaves and woody stem (suppl. Material S5). This was necessary to estimate the proportion of leaves and woody parts of shrubs to account for their different turnover rates (Shaver and Chapin 1991). The dry weight of each plant group including leaves and woody parts of shrubs was measured with a precision scale $( \pm 1 \mathrm{mg})$ and samples were prepared for laboratory analysis of the $\mathrm{C}$ and $\mathrm{N}$ content (NC2500 elemental analyzer, CE Instruments, Milan, Italy). For the laboratory analysis individual and pooled samples were prepared consisting of material of one plant group, and of mixed material from one 
subplot. A total of 126 samples were analyzed (for data see Didion et al. 2018), including 63 individual samples (7 plant groups incl. Leaves and woody parts of shrubs from 9 subregions), and 63 pooled samples (7 mixed samples with typical species composition from 9 subregions).

\section{Analysis}

Addressing the primary objective to develop a model for predicting THL biomass (expressed as dry matter, $\mathrm{g} \cdot \mathrm{m}^{-2}$ ) from the THL cover estimated on each NFI sample plot, the data on the dried plant material from 405 subplots were analyzed in several steps:

i. Analyzing the data for plausibility and agreement with assumptions for regression analysis, i.e. linearity and additivity of the relationship between dependent (biomass) and independent variables.

ii. Identifying parsimonious models for each plant group and for the total herb layer (i.e. over all plant groups) using linear regression and mixed effect models.

iii. Verifying the model for total biomass over all plant groups using independent data from the repeated samples.

The models for the shrub plant group and for the total herb layer were developed for total biomass including woody parts of shrubs (henceforth simply THL) and for total non-woody biomass excluding woody parts of shrubs (henceforth non-woody THL) in order to separate annual biomass components.

The data analysis and model development was carried out in the $\mathrm{R}$ computing environment (version 3.5.1; $\mathrm{R}$ Core Team 2018). The linear mixed-effects models were fitted using the lmer function provided in the 'Ime4' package (Bates et al. 2015). For the final model for total biomass based on cover class, the goal was to keep the model simple. Accordingly, the regression was performed with a minimum set of predicting variables that are available in a consistent manner throughout all NFIs and on all NFI sample plots. As measures of model quality, the relationship between predicted and observed plant biomass was examined using the Pearson productmoment correlation coefficient (Cor.coeff) and the root mean squared error (RMSE). If not otherwise noted, mean and standard deviation are presented in the text.

\section{Results}

As the study was designed to provide a balanced and representative sample of THL cover and biomass, the distribution of cover classes on the subplots that were established on each of the 135 study sites was examined. Each cover class was well represented on the 405 subplots (Table 1). For all examined five cover classes the mean observed percentage THL cover on the subplots and THL cover estimate for the reference plot was greater than the mid-point of a cover class. Of the six plant groups, small herbs occurred most often (325 of 405 subplots) and tall herbs least often (101 of 405 subplots; Table 2). On $85 \%$ of the subplots and on 134 of 135 reference plots two or more plant groups occurred. Shrubs were particularly frequent on subplots with higher percentage cover, i.e. on $80 \%$ of subplots with THL cover $>75 \%$ compared to $42 \%$ on subplots $\leq 50 \%$ THL cover. When present on a subplot, shrubs typically had a higher percentage cover than the other species. Shrub cover was evenly distributed between $1 \%$ and $100 \%$ whereas other species generally had a cover lower than ca. $40 \%$ (Fig. 2).

Table 2 Observed frequency of occurrence and mean $( \pm S D)$ percentage cover and mean $( \pm S D)$ measured biomass as dry matter of individual plant groups on 405 subplots from 135 study sites (3 subplots per site) and on 135 reference plots. Biomass on a reference plots was calculated as the mean of the three subplots. The total herb layer resents all plants found on a subplot or a reference plot but not all plant groups may be present and the composition may be different; see Tables S6-1 and S6-2 for more details

\begin{tabular}{|c|c|c|c|c|c|c|}
\hline \multirow[t]{2}{*}{ Plant group } & \multicolumn{3}{|l|}{ Subplot } & \multicolumn{3}{|l|}{ Reference plot } \\
\hline & Frequency ( $N$ ) & Cover (\%) & Biomass $\left(\mathrm{g} \cdot \mathrm{m}^{-2}\right)$ & Frequency $(N)$ & Cover (\%) & Biomass $\left(\mathrm{g} \cdot \mathrm{m}^{-2}\right)$ \\
\hline Small herbs & 325 & $10.6 \pm 12.7$ & $8.4 \pm 12.7$ & 126 & $7.8 \pm 9.1$ & $7.8 \pm 10.3$ \\
\hline Tall herbs & 101 & $16.4 \pm 22.7$ & $25.6 \pm 41.9$ & 54 & $10.3 \pm 15.0$ & $21.6 \pm 32.5$ \\
\hline Grasses & 159 & $12.9 \pm 18.2$ & $28.6 \pm 57.8$ & 87 & $9.3 \pm 13.6$ & $21.3 \pm 42.9$ \\
\hline Sedges & 196 & $9.4 \pm 14.8$ & $15.6 \pm 32.8$ & 115 & $6.4 \pm 10.7$ & $13.4 \pm 21.4$ \\
\hline Ferns & 174 & $18.7 \pm 21.4$ & $23.3 \pm 39.2$ & 111 & $9.9 \pm 14.1$ & $19.3 \pm 30.7$ \\
\hline Shrubs, incl. Woody parts & 218 & $24.3 \pm 27.1$ & $62.1 \pm 127.2$ & 114 & $16.0 \pm 20.1$ & $49.5 \pm 84.8$ \\
\hline Subsample shrubs ${ }^{a}$, incl. Woody parts & 68 & $18.5 \pm 21.0$ & $37.0 \pm 68.8$ & na & na & na \\
\hline Subsample shrubs ${ }^{a}$, excl. Woody parts & & & $11.7 \pm 16.4$ & na & na & na \\
\hline THL, incl. Woody parts of shrubs & 405 & $43.3 \pm 32.2$ & $75.3 \pm 121.1$ & 135 & $43.6 \pm 31.0$ & $75.3 \pm 106.2$ \\
\hline
\end{tabular}

${ }^{a}$ subsample of subplots with shrub presence where biomass was measured separately for woody and non-woody parts 


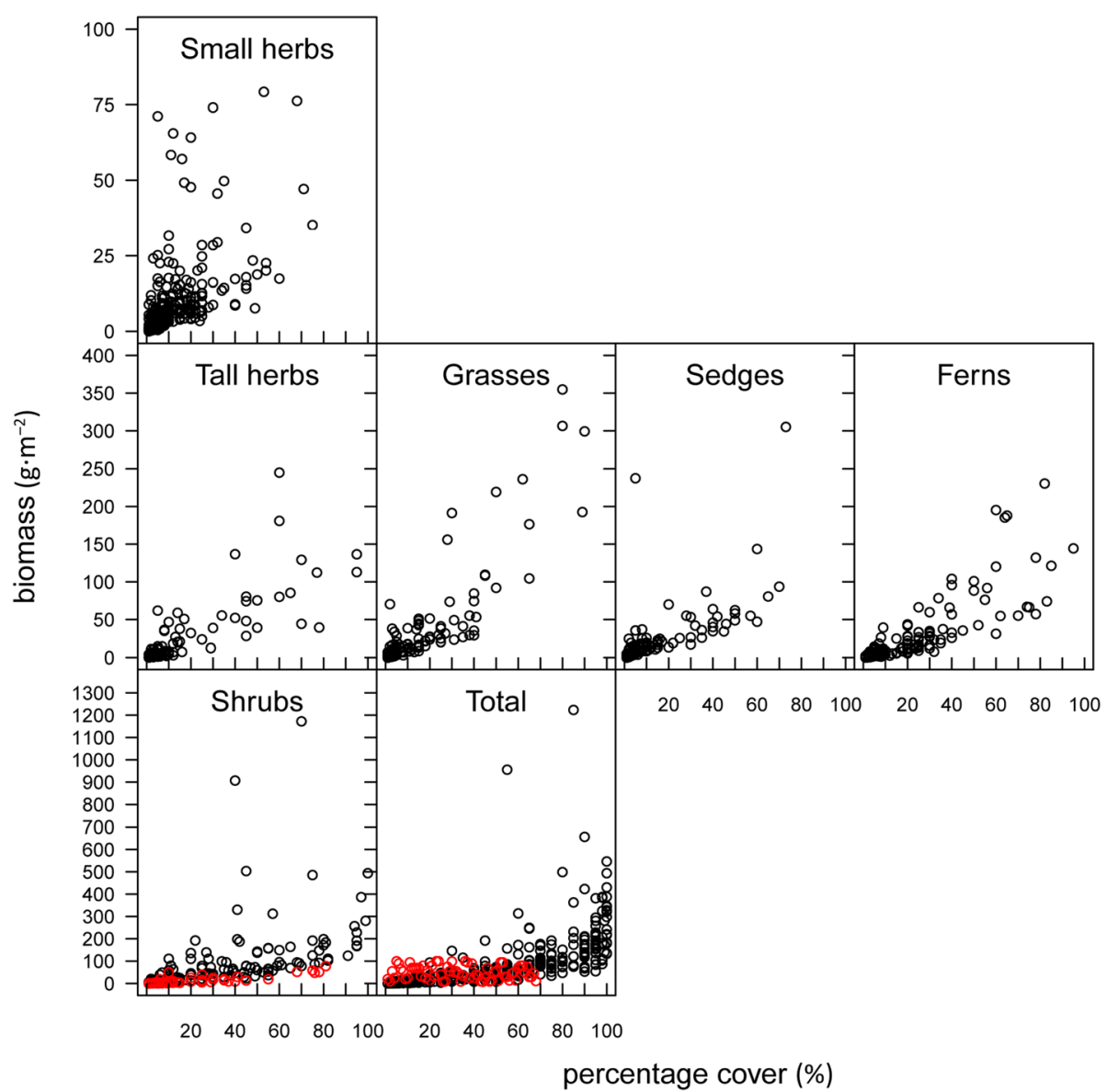

Fig. 2 Observed plant group above-ground biomass (dry matter, $\mathrm{g} \cdot \mathrm{m}^{-2}$ ) and percentage cover. For shrubs and subplot totals black circles indicate observed biomass based on shrubs including woody parts and red circles indicate observed biomass based on shrubs excluding woody parts measured on a subsample $(N=68)$ of subplots with shrub cover. Note the different $y$-axis scales

Biomass on subplots differed between plant groups. Small herbs had the lowest and shrubs including the woody part had the highest biomass (Fig. 2; Table 2). Woody parts of shrubs contributed significantly to THL biomass as they represented on average $42 \% \pm 17 \%$ of the total shrub biomass based on data from 68 subplots where shrub biomass was separated into woody parts and leaves (Fig. S5-1); mean THL and non-woody THL biomass on these 68 subplots were $79.7 \pm 92.9$ and $54.3 \pm 64.0 \mathrm{~g} \cdot \mathrm{m}^{-2}$, respectively (Fig. 2).

There was no statistically significant difference of THL biomass in the nine subregions (Fig. S6-1). Sites in the South tended to have a higher variability and moderately higher biomass than sites in the North. The analysis of the dependent variable biomass did not indicate implausible outliers. Few observations for sedges and shrubs with comparably high values (Fig. 2) could be explained by particularly favorable site conditions or abundant plant growth. The raw biomass data were not normally distributed but could be normalized (ShapiroWilk normality test with $p$ values ranging between 0.11 for shrubs incl. Woody parts and 0.71 for grasses) using a $\log$ transformation (natural Logarithm), which also minimized potential effect of outliers.

Table 3 shows the measured carbon and nitrogen contents of individual plant groups and for shrubs separately for the woody parts and the leaves. The woody parts of shrubs have the highest $\mathrm{C}$ content, shrub leaves, grasses, and sedges have very similar $\mathrm{C}$-contents, and herbs have a little lower $\mathrm{C}$ content. Because the NFI cover data do not include information on the herb layer species composition, $\mathrm{C}$ and $\mathrm{N}$ content was also measured for mixed samples in each strata from subplots with the most frequent plant group composition, including woody parts of shrubs when present (Table S7-1). There was little difference between strata and $C$ content was similar to the values of individual plant groups, i.e. $43.38 \% \pm 2.73 \%$ overall mean including woody parts of shrubs based plant groups (Table 3) and $43.49 \% \pm 1.34 \%$ mean over all strata (Table S7-1). Compared to C contents, $\mathrm{N}$ contents were more variable within species groups and also within strata. 
Table 3 Mean C and N contents (\% of dry biomass) with standard deviation for six plant groups based on 63 samples per plant group, i.e. 7 samples in 9 strata of elevation class (<601, 601-1200, > $1200 \mathrm{~m}$ ) and focal region (North-East, North-West, South)

\begin{tabular}{llr}
\hline Plant group & C-content (\% SD) & N-content (\% \pm SD) \\
\hline Small herbs & $41.55 \pm 1.61$ & $2.31 \pm 0.59$ \\
Tall herbs & $40.08 \pm 2.72$ & $2.19 \pm 0.67$ \\
Grasses & $43.19 \pm 1.39$ & $2.08 \pm 0.48$ \\
Sedges & $43.78 \pm 0.67$ & $1.82 \pm 0.33$ \\
Ferns & $44.69 \pm 1.07$ & $1.88 \pm 0.38$ \\
Shrubs - leaves & $45.90 \pm 1.23$ & $2.04 \pm 0.57$ \\
Shrubs - woody & $46.99 \pm 1.74$ & $1.06 \pm 0.52$ \\
Overall mean incl. Woody parts of shrubs & $43.38 \pm 2.73$ & $1.89 \pm 0.63$ \\
Overall mean excl. Woody parts of shrubs & $43.20 \pm 2.46$ & $2.05 \pm 0.52$ \\
\hline
\end{tabular}

\section{Biomass model}

The statistical analysis of the relationship between percentage cover and dry weight indicated no or only minimal effects of the subplots on the explained variation in plant biomass, i.e. model coefficients estimates, explained variation, and quality were the same or similar for the linear regression model and the mixed effects model. Thus, it could be assumed that the measurements on the three subplots on each study site are independent, and that, considering model parsimony, a simpler linear regression model without random effects suffices. To further justify this, robust linear regression was performed (function rml, MASS package; Venables and Ripley 2002), which returned the same statistical information as the simpler linear regression model. Hence, in the following only results of the linear regression model are presented.

Among the explanatory variables, percentage THL cover and elevation were significant predictors for THL biomass $(p=0)$ explaining together $80 \%$ of the variation in the data. Further explaining variables production region, dominant tree species, forest type, successional stage, cover of tree regeneration, and shrub layer cover explained less than $1 \%$ of the variance, while residual unexplained variation was $19 \%$. The resulting parsimonious model was thus using elevation and percentage THL cover as the only explaining variables. For modelling biomass of individual plant groups, applying a log transformation to the predictor variable percentage cover resulted in the best fit whereas for total subplot biomass the transformation decreased model performance and resulted in a stronger underestimation of observed data (Table S8-1; Fig. S8-1). The final models were thus

$$
\begin{aligned}
\ln \left(\text { biomass }_{\mathrm{pg}}\right)= & \beta_{0}+\beta_{1} \\
& \times \ln \left(\text { percentage } \text { cover }_{\mathrm{pg}}\right) \\
& +\beta_{2} \times \text { elevation }
\end{aligned}
$$

and

$$
\begin{aligned}
\ln \left(\text { biomass }_{\mathrm{THL}}\right)= & \beta_{0}+\beta_{1} \\
& \times \text { percentage cover } \\
& +\beta_{2} \times \text { elevation }
\end{aligned}
$$

where pg is plant group, THL is total herb layer, and $\beta_{0}, \beta_{1}$, and $\beta_{2}$ are model coefficients (Table 4 ). Diagnostics for the selected bivariate linear regression models gave strong evidence that all assumption for a linear regression were met, and no observations with high leverage existed.

Figure 3 shows the results of predicted THL biomass as the sum of the detailed modeling based on individual plant groups (Eq. 1a; mean $60.2 \pm 61.0 \mathrm{~g} \cdot \mathrm{m}^{-2}$ ) and of the model based on the total subplot cover (Eq. 1b) including the woody parts of shrubs (mean $70.5 \pm 96.5 \mathrm{~g} \cdot \mathrm{m}^{-2}$ ). Both approaches moderately underestimate observed biomass (mean $75.3 \pm 121.1 \mathrm{~g} \cdot \mathrm{m}^{-2}$ ) but generally return accurate THL biomass estimates $\left(R^{2}=0.52(p=0)\right.$; Cor.coeff $=0.72(p=0) ; \quad$ RMSE $=84.4 \mathrm{~g} \cdot \mathrm{m}^{-2}$ based on the subplot total; $R^{2}=0.65(p=0)$; Cor.coeff $=0.81 \quad(p=0)$; $\mathrm{RMSE}=81.7 \mathrm{~g} \cdot \mathrm{m}^{-2}$ based on the sum of the model estimates for individual plant groups).

The model for THL biomass (Eq. 1b) was also fitted to data from 255 subplots without shrub occurrence $(N=$ 187 ) or with shrub occurrence and measured woody and non-woody shrub biomass $(n=68)$ but excluding the woody parts. Accuracy of this model was also high $\left(R^{2}=\right.$ $0.76(p=0)$; Cor coeff $=0.88(p=0) ; \mathrm{RMSE}=29.3 \mathrm{~g} \cdot \mathrm{m}^{-2}$, cf. Table 4) predicting a mean non-woody THL biomass over all 405 subplots of $54.9 \pm 72.3 \mathrm{~g} \cdot \mathrm{m}^{-2}$.

\section{Biomass model for plant cover class}

Since one purpose of this study was to develop a model to estimate THL biomass based on the categorical cover estimated over all six plant groups on each regular NFI sample plot, the information developed in the previous steps was extended. Based on the findings for percentage cover, the linear regression model was adapted for cover class: 
Table 4 Coefficients with standard error of bivariate linear regression model (Eq. 1a for plant groups and Eq. 1b for total herb layer) between total above-ground biomass and percentage cover and elevation for plant groups and herb layer total on subplots, and explained variation $\left(R^{2}\right)$, Pearson product-moment correlation coefficient (Cor.coeff) and root mean squared error (RMSE). See Table 2 for sample size. Note that for modeling, percent cover of plant group is transformed using the natural logarithm, total herb layer cover is not transformed

\begin{tabular}{|c|c|c|c|c|c|c|}
\hline Plant group & $\boldsymbol{\beta}_{\mathbf{0}}$ (Intercept) & $\boldsymbol{\beta}_{\mathbf{1}}$ (Percent Cover) & $\boldsymbol{\beta}_{\mathbf{2}}$ (Elevation) & Adj. $R^{2}$ & Cor.coeff & RMSE $\left(g \cdot m^{-2}\right)$ \\
\hline Small herbs & $\begin{array}{l}-0.5935310 \text { *** } \\
(0.1274447)\end{array}$ & $0.9039098^{* * *}(0.0387518)$ & $0.0003887 * * *(0.0001068)$ & $\begin{array}{l}0.63 \\
* * *\end{array}$ & $0.63 * *$ & 10.1 \\
\hline Tall herbs & $-0.3404689(0.2858600)$ & $1.0773257 * * *(0.0624539)$ & $0.0002557(0.0002246)$ & $\begin{array}{l}0.75 \\
* * *\end{array}$ & $0.81 * * *$ & 25.1 \\
\hline Grasses & $-0.1751947(0.1818310)$ & $1.1453724 * * *(0.0481618)$ & $0.00006194^{\circ}(0.0001502)$ & $\begin{array}{l}0.79 \\
* * *\end{array}$ & $0.91 * * *$ & 28.5 \\
\hline Sedges & $-0.1314442(0.1536686)$ & $1.1004399 * * *(0.0432052)$ & $0.0003158 *(0.0001321)$ & $\begin{array}{l}0.77 \\
* * *\end{array}$ & $0.68 * * *$ & 24.2 \\
\hline Ferns & $\begin{array}{l}-0.6882659 \text { **** } \\
(0.1569825)\end{array}$ & $1.1599828^{* * *}(0.0390035)$ & $0.0001060(0.0001206)$ & $\begin{array}{l}0.84 \\
* * *\end{array}$ & $0.83 * * *$ & 23.8 \\
\hline Shrubs & $\begin{array}{l}-0.8868706 \text { *** } \\
(0.1464385)\end{array}$ & $1.1755751 * * *(0.0321635)$ & $0.0009174 * * *(0.0001047)$ & $\begin{array}{l}0.86 \\
* * *\end{array}$ & $0.77^{* * *}$ & 88.9 \\
\hline Shrubs leaves ${ }^{1}$ & $\begin{array}{l}-0.54936569 * \\
(0.27448296)\end{array}$ & $\begin{array}{l}0.94944646 * * * \\
(0.06683793)\end{array}$ & $0.00004201(0.00019741)$ & $\begin{array}{l}0.75 \\
* * *\end{array}$ & $0.83 * * *$ & 10.1 \\
\hline $\begin{array}{l}\text { Total, incl. Woody parts of } \\
\text { shrubs }\end{array}$ & $\begin{array}{l}0.98555045 \text { *** } \\
(0.09465661)\end{array}$ & $\begin{array}{l}0.04150483^{* * *} \\
(0.00106115)\end{array}$ & $\begin{array}{l}0.00061034 * * * \\
(0.00008286)\end{array}$ & $\begin{array}{l}0.80 \\
* * *\end{array}$ & $0.72 * * *$ & 84.4 \\
\hline $\begin{array}{l}\text { Total, excl. Woody parts of } \\
\text { shrubs }{ }^{2}\end{array}$ & $1.0841536 * * *(0.1165718)$ & $0.0414646 * * *(0.0014661)$ & $0.0002700 *(0.0001085)$ & $\begin{array}{l}0.76 \\
* * *\end{array}$ & $0.88 * * *$ & 29.3 \\
\hline
\end{tabular}

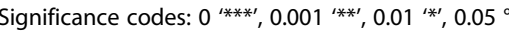

${ }^{1}$ subsample of 68 subplots with measured woody and non-woody shrub biomass from the total 218 subplots with shrub cover

${ }^{2}$ subsample of 255 subplots without shrub occurrence $(N=187)$ as well as subplots with measured woody and non-woody shrub biomass ( $\left.n=68\right)$ but excluding the woody parts

$$
\begin{aligned}
\ln \left(\text { biomass }_{\mathrm{THL}}\right)= & \beta_{0}+\beta_{1} \times \text { cover class }_{\mathrm{THL}} \\
& +\beta_{2} \times \text { elevation }
\end{aligned}
$$

where THL is total herb layer, and $\beta_{0}, \beta_{1}$, and $\beta_{2}$ are model coefficients.

The model was used to predict THL biomass based on cover class and elevation as predictors (Table 5). The reduced accuracy due to the use of cover classes instead of absolute percentage cover (Eq. 1b) did not affect model performance $\left(R^{2}=0.83(p=0)\right.$; cor.coeff $=0.75(p=0)$; RMSE $\left.=82.6 \mathrm{~g} \cdot \mathrm{m}^{-2}\right)$. Except for cover class $2(1 \%-9 \%$ cover), there was no statistically significant difference at $p=0.05$ between observed and predicted THL biomass within individual cover classes (Table 5).

Similar to the model for percentage cover, the modified model for cover class was also used to predict nonwoody THL biomass based on cover class and elevation as predictors (Fig. 4; Table 6). The explained variance $\left(R^{2}=0.79, p=0\right)$ and correlation (Cor.coeff $\left.=0.82, p=0\right)$ were of the same size as for the total biomass, and RMSE $\left(33.2 \mathrm{~g} \cdot \mathrm{m}^{-2}\right)$ was less than half. A comparison between observed and predicted non-woody THL biomass based on 255 subplots without or with shrub presence and measured woody and non-woody shrub biomass (Table 6) showed no statistically significant difference for cover classes 3 to 6 , i.e. cover $\geq 10 \%$.

\section{Site level biomass}

THL biomass of the reference plot was calculated as the mean of woody and non-woody biomass, respectively, measured on three subplots on each study site. THL cover class that was estimated at the level of the reference plot was used to predict site level biomass. This approach corresponds to the intended application to estimate THL and non-woody THL biomass on each NFI sample plot. The adapted model to predict THL biomass based on cover class and elevation (Eq. 2) was applied to estimate biomass on the scale of a reference plot. THL biomass on the 135 sites was reproduced well by the model predicting a mean of $63.7 \pm 73.5 \mathrm{~g} \cdot \mathrm{m}^{-2}$ (Fig. $5 ; R^{2}=0.72(p=0)$, Cor.coeff $=0.85(p=0)$, RMSE $\left.59.3 \mathrm{~g} \cdot \mathrm{m}^{-2}\right)$. Predicted mean non-woody THL biomass was $45.1 \pm 46.3 \mathrm{~g} \cdot \mathrm{m}^{-2}$ for all 135 subplots, and $63.7 \pm$ $73.5 \mathrm{~g} \cdot \mathrm{m}^{-2}$ for reference plots without shrub presence.

\section{Model evaluation and verification}

The coefficients of the model for non-woody THL biomass and absolute percentage cover (Table 4) were estimated based on data from all subplots without shrub-presence or with shrub-presence and measured shrub leaves (i.e. 255 of 405 subplot). To evaluate a potential bias introduced by the reduction in sample number and by accounting for non-woody parts of shrubs only, model coefficients were 


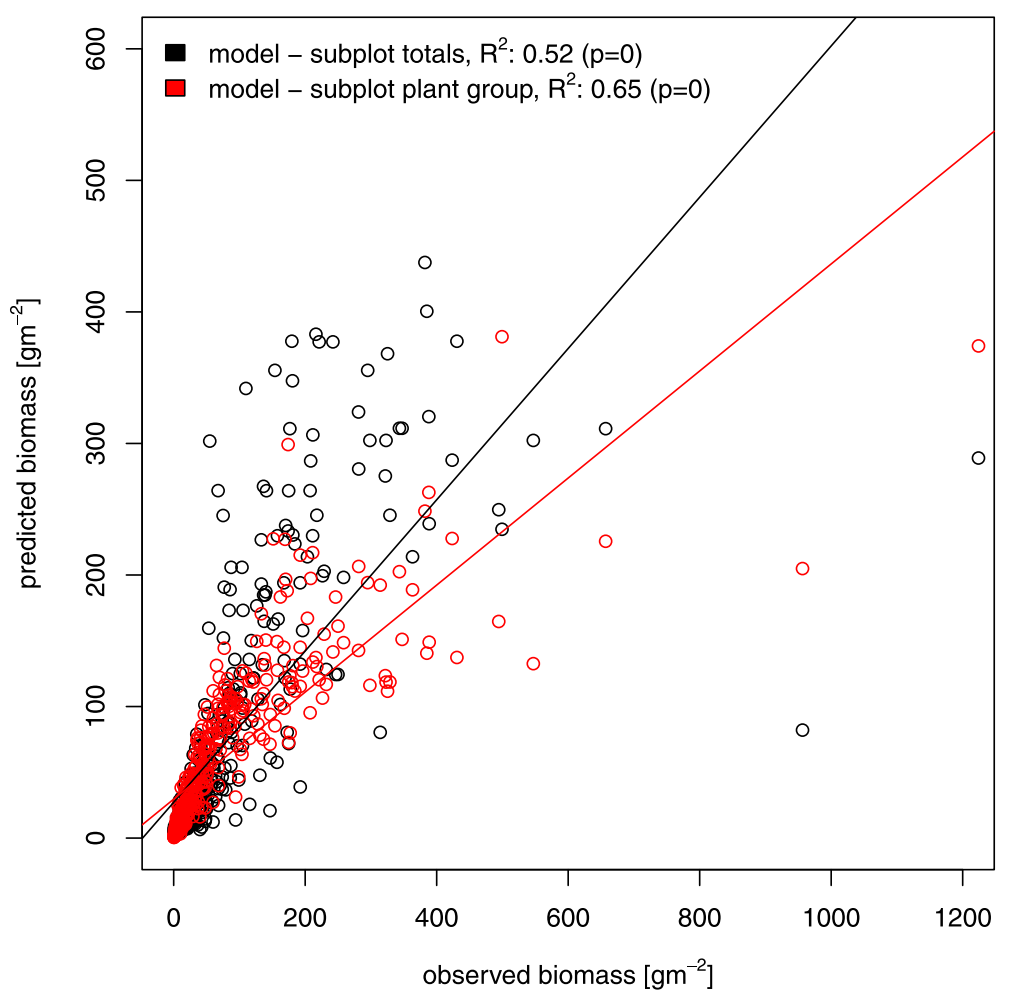

Fig. 3 Observed and predicted total above-ground biomass including woody parts of shrubs (dry matter, $g \cdot \mathrm{m}^{-2}$ ). Black circles show the results of the model for subgroup totals, and red circles show the results of the explicit modeling of each plant group with the plant group prediction summed up to the subplot total. The lines indicate the relationship between predicted and observed values

estimated based on two alternative subsets of the subplot data (Table S10-1): i) subplots with measured woody and non-woody shrub biomass $(n=68)$, ii) subplots without shrub occurrence $(N=187)$. No statistically significant differences between the alternative model implementations existed (Fig. S10-1). This result gave strong evidence that the model to predict THL biomass (Eq. 1b) using percent THL cover and elevation as predictors is also applicable to estimate non-woody THL biomass (i.e. excluding woody parts of shrubs).
The model to predict total above-ground plant biomass based on absolute percentage cover and elevation at the subplot level (Eq. 1b) was applied to predict biomass at sites below $600 \mathrm{~m}$ (suppl. Material S2). The model predicted total subplot $(N=27)$ plant biomass based on the independent plant cover estimates at visits $\# 2$ and \#3 accurately (Fig. 6). From visit \#1 to \#3, Fig. 6 indicates an increase in observed and a decrease in predicted total biomass. The increase in the observed biomass is supported by the collected data (i.e. mean and standard deviation of total biomass from 27 repeatedly

Table 5 Coefficients and standard error of standard linear regression model (Eq. 2) between total above-ground biomass including woody parts of shrubs and cover class and elevation on subplots. For each cover class mean ( \pm SD) observed and predicted biomass is presented; see Table 1 for sample size

\begin{tabular}{llllll}
\hline & & Estimate & Standard error & Observed subplot biomass $\left(\mathrm{g} \cdot \mathrm{m}^{\mathbf{- 2}}\right)$ & Predicted subplot biomass $\left(\mathrm{g} \cdot \mathrm{m}^{\mathbf{- 2}}\right)$ \\
\hline$\beta_{0}$ & Intercept & $0.66864027^{* * *}$ & 0.10240013 & na & na \\
$\beta_{1}$ & cover class 2 & na & na & $4.9 \pm 3.9$ & $3.6 \pm 0.9$ \\
& cover class 3 & $1.29273989^{* * *}$ & 0.09922620 & $15.5 \pm 12.4$ & $12.8 \pm 3.1$ \\
& cover class 4 & $2.24503984^{* * *}$ & 0.10221280 & $39.1 \pm 28.6$ & $33.5 \pm 8.4$ \\
& cover class 5 & $3.08838612^{* * *}$ & 0.10419718 & $99.6 \pm 114.4$ & $80.5 \pm 23.1$ \\
& cover class 6 & $3.95982283^{* * *}$ & 0.10221464 & $223.2 \pm 167.6$ & $190.5 \pm 55.9$ \\
$\beta_{2}$ & Elevation & $0.00062006^{* * *}$ & 0.00007718 & na & na
\end{tabular}

Significance codes: 0 ****'0.001 ${ }^{* * * \prime} 0.01^{* *} 0.05^{\circ}$ 


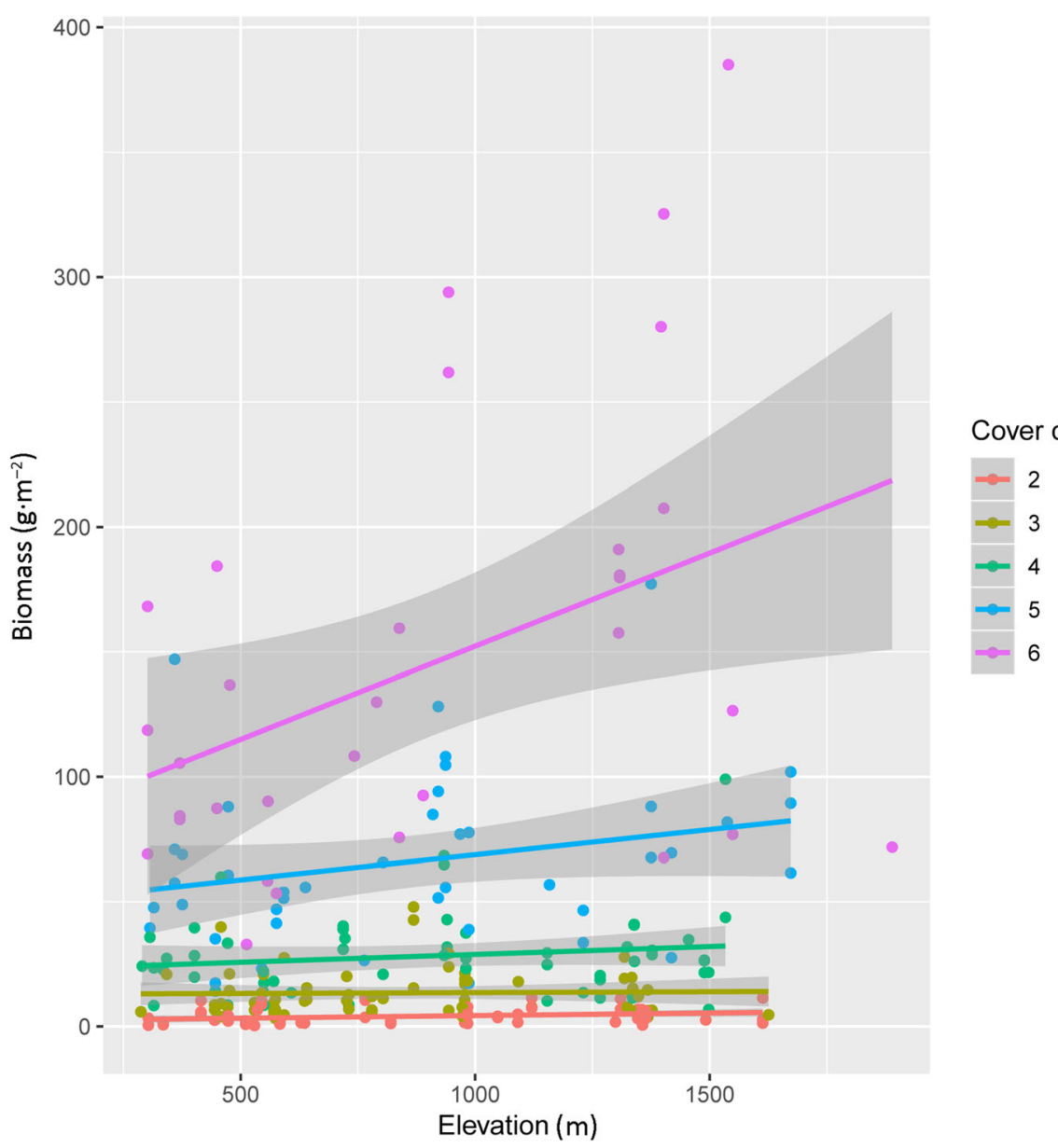

Fig. 4 Observed (points) total non-woody above-ground biomass (dry matter, $\mathrm{g} \cdot \mathrm{m}^{-2}$ ) on subplots and linear regression model fit (cf. Table 6) for data from 255 subplots without shrub occurrence $(N=187)$ as well as subplots with measured woody and non-woody shrub biomass ( $n=68)$ but excluding the woody parts. Shaded areas indicate the respective 95\% confidence intervals. Fig. S9-1 presents the data for total above ground biomass including woody parts of shrubs

Table 6 Coefficients and standard error of standard linear regression model (Eq. 2) between total non-woody above-ground biomass from subplots without shrub occurrence $(N=187)$ as well as subplots with measured woody and non-woody shrub biomass ( $n=68$ ) but excluding the woody parts (i.e. total $N=255$ ) and cover class and elevation on subplots. For each cover class mean $( \pm \mathrm{SD}$ ) observed and predicted biomass is presented; see Table 1 for sample size

\begin{tabular}{|c|c|c|c|c|c|}
\hline & & Estimate & Standard error & Observed subplot biomass $\left(\mathrm{g} \cdot \mathrm{m}^{-2}\right)$ & Predicted subplot biomass $\left(\mathrm{g} \cdot \mathrm{m}^{-\mathbf{2}}\right)$ \\
\hline$\beta_{0}$ & Intercept & $0.7716507^{* * *}$ & 0.1232084 & na & na \\
\hline \multirow[t]{5}{*}{$\beta_{1}$} & Cover class 2 & na & na & $4.1 \pm 3.2$ & $3.0 \pm 0.4$ \\
\hline & Cover class 3 & $1.3341515^{* * *}$ & 0.1155178 & $13.5 \pm 9.3$ & $11.4 \pm 1.5$ \\
\hline & Cover class 4 & $2.0968932 * * *$ & 0.1199388 & $28.3 \pm 16.6$ & $24.6 \pm 3.5$ \\
\hline & Cover class 5 & $2.9866689^{* * *}$ & 0.1294084 & $66.3 \pm 33.7$ & $60.9 \pm 9.8$ \\
\hline & Cover class 6 & $3.7241023 * * *$ & 0.1409310 & $145.1 \pm 86.3$ & $126.5 \pm 20.8$ \\
\hline$\beta_{2}$ & Elevation & $0.0003537^{* * *}$ & 0.0001020 & na & na \\
\hline
\end{tabular}

Significance codes: 0 '***', $0.001^{\prime * * \prime}, 0.01^{\prime *}, 0.05^{\circ}$ 


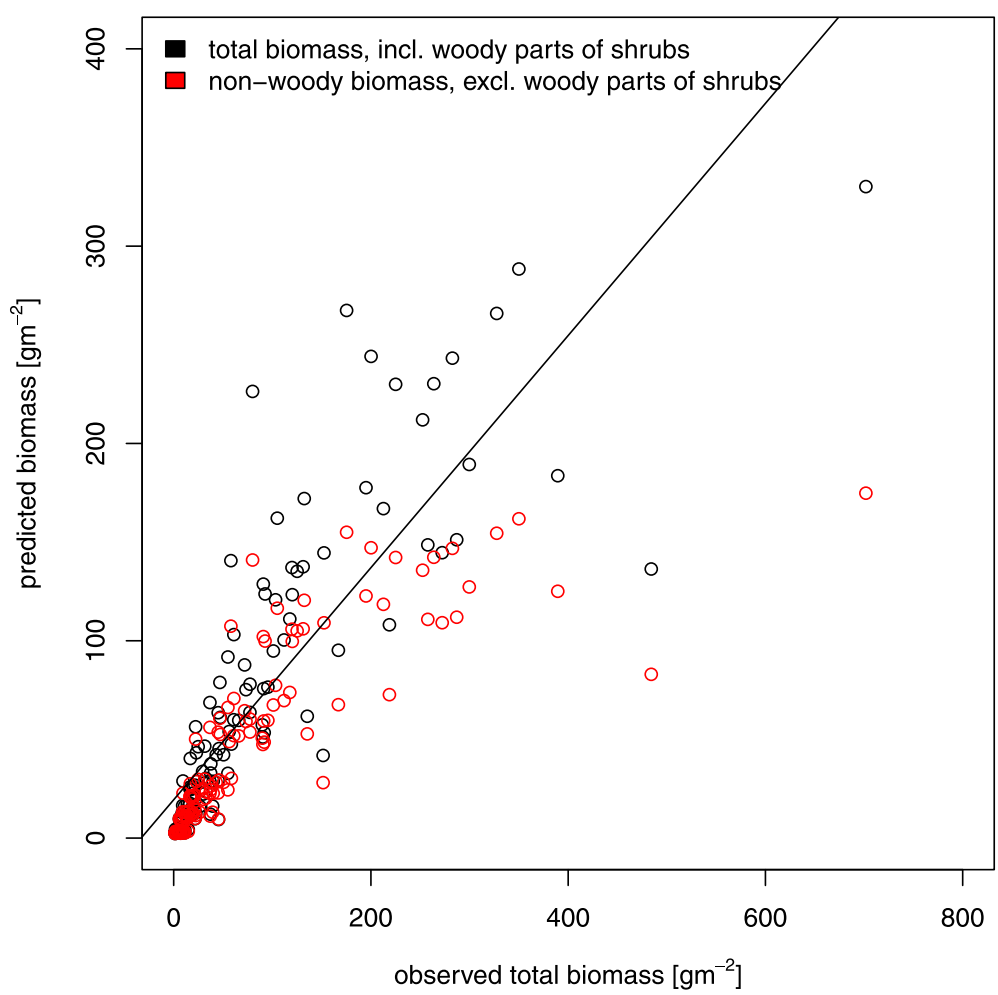

Fig. 5 Observed and predicted total (i.e. incl. Woody parts of shrubs) above-ground biomass at 135 study sites $Z$ at the scale of a $50 \mathrm{~m} \times 50 \mathrm{~m}$ reference plot. For comparison predicted total non-woody ABG is shown in red circles. The line indicates the relationship between predicted and observed values

sampled subplots in visits \#1, \#2, and \#3 were $100.1 \pm$ $69.3,129.3 \pm 132.8$, and $135.0 \pm 148.1 \mathrm{~g} \cdot \mathrm{m}^{-2}$, respectively). However, there was also a decrease in observed cover from $69 \% \pm 28 \%$ to $68 \% \pm 29 \%$ and $65 \% \pm 27 \%$ mean cover on the 27 subplots, which was responsible for the decrease in predicted biomass. The diverging trends in the observations, i.e. increasing biomass and decreasing percentage cover, were due to primarily two reasons: height growth and also larger leaf size. These processes were also responsible for an increasing range and variability in the measured biomass without observable change in cover.

Absolute percentage cover and THL biomass at the level of the $50 \mathrm{~m} \times 50 \mathrm{~m}$ reference plot $(N=9)$ differed very little over the tree visits (Table S2-1 and Fig. S2-1). Consequently, predicted biomass over time is more consistent at this scale (Fig. 6). Following the consistent estimates of THL percentage cover, THL cover classes did not change over time and, hence, predicted biomass using the model based on cover classes (Eq. 2) is constant over time.

\section{Model application to predict herb layer biomass on regular national forest inventory plots}

Applying the developed model to predict THL and nonwoody THL biomass based on cover class (Eq. 2, Table 6), biomass was estimated for each accessible sample plot excluding brush forests in the Swiss NFIs 2, 3 , and 4 based on the observed THL cover class and elevation of a plot. The mean and the standard error of THL biomass were $908.6 \pm 13.5 \mathrm{~kg} \cdot \mathrm{ha}^{-1}$ in the NFI2 $(N=5679), 899.8 \pm 13.3 \mathrm{~kg} \cdot \mathrm{ha}^{-1}$ in the NFI3 $(N=5920)$, and $932.0 \pm 14.0 \mathrm{~kg} \cdot \mathrm{ha}^{-1}$ in the NFI4 $(N=6042)$. The corresponding values for non-woody THL biomass were $586.6 \pm 7.7,575.2 \pm 7.6$, and $586.7 \pm 7.9 \mathrm{~kg} \cdot \mathrm{ha}^{-1}$, respectively. Based on the mean $\mathrm{C}$ content of non-woody biomass (Table 3), the total herb layer adds annually approximately $253.0 \pm 3.3 \mathrm{~kg} \mathrm{C} \cdot \mathrm{ha}^{-1}$ (NFI2), $248.5 \pm 3.3$ $\mathrm{kg} \mathrm{C} \cdot \mathrm{ha}^{-1}$ (NFI3), and $253.0 \pm 3.4 \mathrm{~kg} \mathrm{C} \cdot \mathrm{ha}^{-1}$ to the mean above-ground non-woody $\mathrm{C}$ produced by the tree layer in Swiss forest. On $75 \%$ of the NFI sampling plots, this corresponds to $1 \%$ to $35 \%$ (median $10 \%$ ) of the current estimates of $\mathrm{C}$ inputs from tree foliage (Didion and Thürig 2018). On plots with open forest such as in young forests or after a disturbance, the contribution of the herb layer can increase significantly to exceed the $C$ inputs from tree foliage.

\section{Discussion}

The findings of this study support results of several other studies showing that plant cover of herb layer species is a good predictor of their biomass (e.g. Muukkonen et al. 2006; Heinrichs et al. 2010; Johnson et al. 


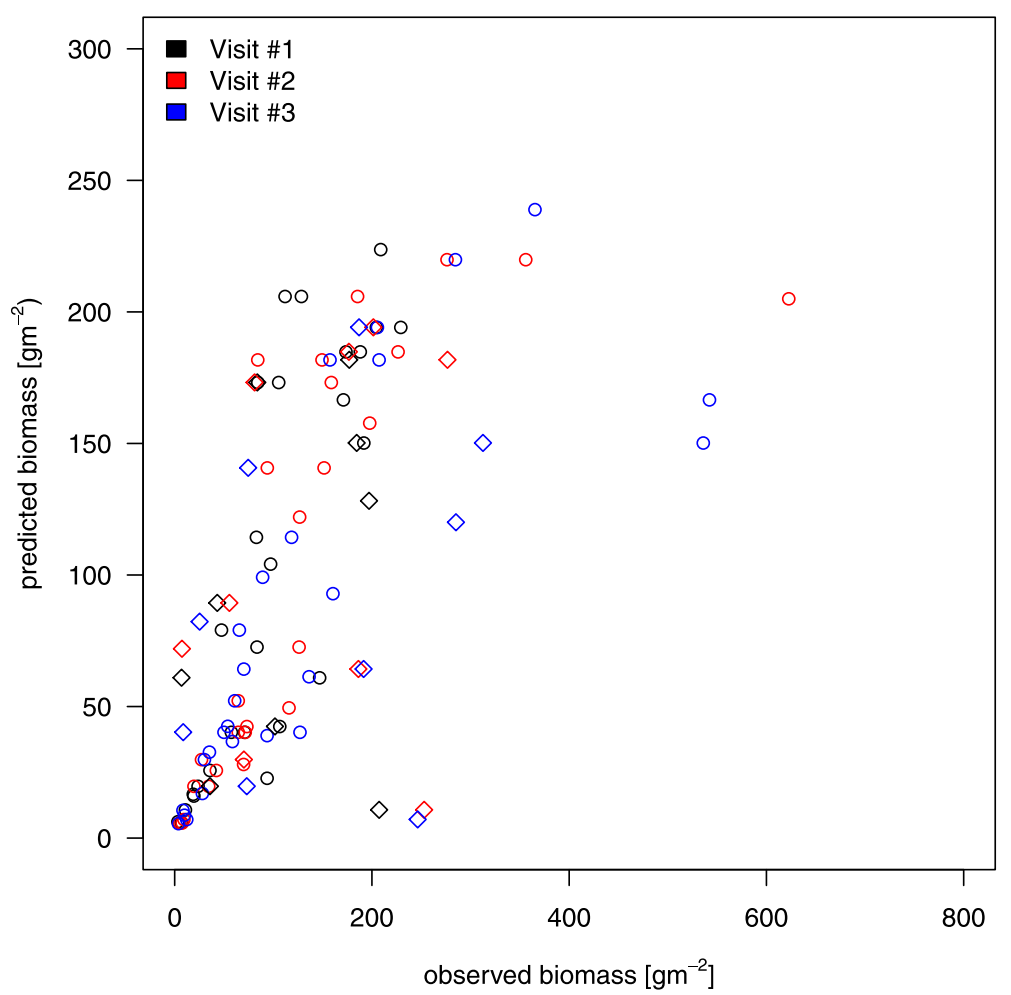

Fig. 6 Observed and predicted total herb layer above-ground biomass on subplots open circles; $N=27$ ) and reference plots (diamonds; $N=9$ ) (dry matter, $\mathrm{g} \cdot \mathrm{m}^{-2}$ ) on 3 revisited study sites below $600 \mathrm{~m}$ in 3 cluster regions with 3 independent subplots at each site and visit. Observed data from visit \#1 were already used in model development, data from visits \#2 and \#3 are considered independent observations

2017). The study also demonstrates that total herb layer cover estimated over all species is a good predictor for the whole herb layer biomass. This is consistent with findings by Muukkonen and Mäkipää (2006) who showed this for more uniform forests and fewer plant species in the herb layer. Since the present study covered a larger gradient of forest types with a high heterogeneity in forest structure and herb layer plant composition, it extends on previous studies and validates the correlation between total herb layer cover and biomass for application with cover data collected in NFIs.

The comprehensive data collection in this study allowed the development of models for individual plant groups (Eq. 1a) as well as for the total herb layer (Eq. 1b). Since the herb layer typically comprises more than one plant group, cover of individual plant groups was estimated as the relative contribution to total herb layer cover. This was important since models such PhytoCalc, which estimate biomass of individual plant groups based on their individually estimated absolute cover (Schulze et al. 2009; Heinrichs et al. 2010) are not applicable for use with THL cover estimates. The finding that observed THL biomass was reproduced more accurately with untransformed cover data was reassuring as loglog models can result in biased estimates and require the application of correction factors (Clifford et al. 2013).
The good agreement between the THL biomass estimates derived from summation of predictions for individual plant groups and directly from THL cover (Fig. 3) further demonstrates the suitability of the approach in this study for application with aggregated data at the scale of regional or national forest inventories. The comprehensive and large-scale approach of this study covering the complete range of percentage THL cover ( $\mathrm{min}$. 1\%, max. 100\%, Fig. 2, Table S6-1) and a wide range of THL biomass (min. $0.4 \mathrm{~g} \cdot \mathrm{m}^{-2}$, max. $1224.1 \mathrm{~g} \cdot \mathrm{m}^{-2}$, Fig. 2, Table S6-2), as well as a large gradient of forest conditions (Tables S1-1 to S1-5), also ensured that the developed model coefficients are representative and suitable for predictions over a wide range minimizing the need for extrapolation outside the range of observed data.

Muukkonen and Mäkipää (2006) and Muukkonen et al. (2006) presented a methodology to estimate herb layer biomass in boreal forests covered by the Finnish NFI and limited to two forest types and excluding ferns in the herb layer. The current study presents the first model that is comprehensive of the total herb layer and that can be applied in a consistent manner at the national scale. The estimates of this study for the mean total non-woody herb layer above-ground biomass in Swiss forests provide empiric evidence to findings from 
metastudies (e.g. Gilliam 2007) that the herb layer in forests can contribute significantly to annual net primary productivity and even more so to annual litterfall. The estimated median THL contribution of approximately $10 \%$ to annual litterfall in Swiss forests agrees well with estimates reported in Gilliam (2007) or in Welch et al. (2007). The results are also consistent with findings of de Wit et al. (2006), who report that $C$ inputs from litter produced by ground vegetation can account for almost all $\mathrm{C}$ inputs in recently harvested stands and between $10 \%$ to $50 \%$ in middle-aged and old stands.

In this study, no or only weak correlations were found between herb layer cover and other forest attributes such as over- and midstory tree and shrub vegetation, which were identified as important driver in relevant studies (e.g. Muukkonen and Mäkipää 2006; Landuyt et al. 2019b). This may be due to the typically heterogeneous forest structure in Switzerland (Thürig and Kaufmann 2010) preventing single attributes to become dominant drivers at the national scale of the NFI. The forest heterogeneity may also be the driver of the comparably high herb layer diversity, which was found in this study (Table 2). The finding that the total herb layer biomass was predicted with the same or even better accuracy than individuals plant groups (Table 4) supports this hypothesis. It suggests that competition between plant groups may cause a high variability in the individual plant group biomass but that this effect is less noticeable considering the total biomass on a subplot.

The high variability in herb layer biomass also affects the uncertainty associated with the model prediction, which increases with increasing herb layer cover (Fig. 4). In large scale applications such as for cover data from NFIs with large sample sizes, it can be expected that this effect is minimized for the mean estimate (Melo et al. 2018). A reduction of variability in observed and predicted THL biomass could be achieved by using narrower intervals for cover classes improving accuracy of predicted biomass (Alberdi et al. 2018). As shown in this study, experienced field crews estimate cover very consistently, which is supported by the data from the repeated sample (Table S2-1).

Consistency in the estimates of THL cover is important as NFI samples plots are visited between spring and fall and the stage of herb layer cover may differ between plots. Inconsistent cover estimates would introduce additional uncertainty in the biomass estimates, which could not be quantified. Quantification of uncertainty is important however to ensure transparency and comparability of data. This is particularly true in cases where herb layer biomass estimates are used for reporting, for example in Forest Resource Assessments of the FAO or in greenhouse gas inventories under the UNFCCC or the Kyoto Protocol.

\section{Conclusions}

In many countries NFIs provide important on timber resources and increasingly additional observation are included. It is important to make the most use of them. In this study a commonly observed attribute herb layer cover was applied to obtain biomass estimates in a harmonized and standardized methodology applicable to NFIs applying the ENFIN definition of the herb layer. A comprehensive data set ensured that the developed model to estimate herb layer biomass is representative of the forest herb layer at large scales representing a high variability of forest environments.

The model is parsimonious requiring only readily available elevation data of sample plots in addition to NFI cover estimates. The study demonstrated that the presented approach is suitable for use with NFI data and provides unbiased estimates at the national scale. These qualities are particularly important for applications requiring transparent methodologies that result in accurate, consistent, and comparable data such as international reporting for Forest Resource Assessments or greenhouse gas inventories.

\section{Supplementary information}

Supplementary information accompanies this paper at https://doi.org/10. 1186/s40663-020-00230-7.

\section{Additional file 1.}

\section{Acknowledgements}

J. Schneuwly (internship student) and NFI scientific collaborators M. Baume and F. Giudici were responsible for the meticulous and efficient work in the field. Valuable advice on the implementation of the project were made by $F$. Cioldi, C. Düggelin, M. Keller, A. Kupferschmid, P. Waldner and M. Walser (all WSL). Work material was provided by the NFI (F. Cioldi) and M. Walser. Comments to earlier versions of the manuscript by N. Rogiers and F. Giudici are gratefully acknowledged. We further appreciate the valuable comments of two anonymous reviewers.

Authors' contributions

MD conceived and planned the study, analyzed the data, and wrote the manuscript. The author read and approved the final manuscript.

\section{Funding}

The project was supported financially by the Swiss Federal Office for the Environment (FOEN) (project monitoring by N. Rogiers, contract no.: 06.0091. PZ/P043-0606). M. Didion received financial support from FOEN.

\section{Availability of data and materials}

The datasets generated and/or analyzed during the current study are available in the Envidat repository (https://www.envidat.ch/\#/metadata/herblayer-biomass-in-swiss-forests).

Ethics approval and consent to participate

Not applicable.

Consent for publication

Not applicable.

Competing interests

The author declares that there are no competing interests. 
Received: 22 December 2019 Accepted: 12 March 2020

\section{10.0}

\section{References}

Alberdi I, Condés S, Martínez-Millán J (2010) Review of monitoring and assessing ground vegetation biodiversity in national forest inventories. Environ Monit Assess 164:649-676. https://doi.org/10.1007/s10661-009-0919-4

Alberdi I, Condés S, Mcroberts RE, Winter S (2018) Mean species cover: a harmonized indicator of shrub cover for forest inventories. Eur J Forest Res 137:265-278. https://doi.org/10.1007/s10342-018-1110-7

Bates D, Maechler M, Bolker B, Walker S (2015) Fitting linear mixed-effects models using Ime4. J Stat Software 67:1-48. https://doi.org/10.18637/jss.v067.01

Brändli U-B, Hägeli M (2019) Swiss NFI at a glance. In: Fischer C, Traub B (eds) Swiss National Forest Inventory - methods and models of the fourth assessment. Springer International Publishing, Cham, pp 3-35. https://doi. org/10.1007/978-3-030-19293-8_1

Chirici G, McRoberts RE, Winter S, Barbati A, Brändli U, Abegg M, Beranova J, Rondeux J, Bertini R, Asensio IA, Condés S (2011) Harmonization tests. In: Chirici G, Winter S, McRoberts RE (eds) National Forest Inventories: contributions to Forest biodiversity assessments. Springer Netherlands, Dordrecht, pp 121-190. https://doi.org/10.1007/978-94-007-0482-4_5

Clifford D, Cressie N, England JR, Roxburgh SH, Paul KI (2013) Correction factors for unbiased, efficient estimation and prediction of biomass from log-log allometric models. Forest Ecol Manag 310:375-381. https://doi.org/10.1016/j. foreco.2013.08.041

Core Team R (2018) R: a language and environment for statistical computing. R Foundation for Statistical Computing, Vienna https://www.R-project.org/

Davis GE (1993) Design elements of monitoring programs: the necessary ingredients for success. Environ Monit Assess 26:99-105. https://doi.org/10. 1007/bf00547489

de Wit HA, Palosuo T, Hylen G, Liski J (2006) A carbon budget of forest biomass and soils in Southeast Norway calculated using a widely applicable method. Forest Ecol Manag 225:15-26

Didion M, Baume M, Giudici F, Schneuwly J (2018) Herb layer cover and biomass data from Swiss forests. Swiss Federal Research Institute WSL, Birmensdorf https://doi.org/10.16904/envidat.52. Accessed 22 Dec 2019

Didion M, Thürig E (2018) Data on soil carbon stock change, carbon stock and stock change in surface litter and in coarse deadwood prepared for the Swiss GHGI 2019 (1990-2017). Swiss Federal Institute for Forest. Snow and Landscape Research WSL, Birmensdorf http:// www.bafu.admin.ch/bafu/en/ home/topics/climate/state/data/climate-reporting.html. Accessed 22 Dec 2019

Düggelin C, Keller M (eds) (2017) Schweizerisches Landesforstinventar: Feldaufnahme - Anleitung 2017 [Swiss National Forest Inventory: Field manual 2017]. Swiss Federal Institute for Forest, Snow and Landscape Research, Birmensdorf (ZH), p 220

FOEN(Federal Office for the Environment) (2019) Switzerland's greenhouse gas inventory 1990-2017. National Inventory Report including reporting elements under the Kyoto protocol. Submission of April 2019 under the United Nations framework convention on climate change and under the Kyoto protocol. Federal Office for the Environment, Bern http://www.bafu admin.ch/climatereporting. Accessed 22 Dec 2019

Gilliam FS (2007) The ecological significance of the herbaceous layer in temperate Forest ecosystems. BioScience 57:845-858. https://doi.org/10. 1641/b571007

Heinrichs S, Bernhardt-Römermann M, Schmidt W (2010) The estimation of aboveground biomass and nutrient pools of understorey plants in closed Norway spruce forests and on clearcuts. Eur J For Res 129:613-624. https:// doi.org/10.1007/s10342-010-0362-7

Johnson KD, Domke GM, Russell MB, Walters B, Hom J, Peduzzi A, Birdsey R, Dolan K, Huang W (2017) Estimating aboveground live understory vegetation carbon in the United States. Environ Res Lett 12:125010. https://doi.org/10. 1088/1748-9326/aa8fdb

Kumar P, Chen HYH, Searle EB, Shahi C (2018) Dynamics of understorey biomass, production and turnover associated with long-term overstorey succession in boreal forest of Canada. Forest Ecol Manag 427:152-161. https://doi.org/10. 1016/j.foreco.2018.05.066

Landuyt D, Lombaerde ED, Perring MP, Hertzog LR, Ampoorter E, Maes SL, Frenne PD, Ma S, Proesmans W, Blondeel H, Sercu BK, Wang B, Wasof S, Verheyen K (2019a) The functional role of temperate forest understorey vegetation in a changing world. Glob Chang Biol 25:3625-3641. https://doi. org/10.1111/gcb.14756

Landuyt D, Maes SL, Depauw L, Ampoorter E, Blondeel H, Perring MP, Brūmelis G, Brunet J, Decocq G, den Ouden J, Härdtle W, Hédl R, Heinken T, Heinrichs S, Jaroszewicz B, Kirby KJ, Kopecký M, Máliš F, Wulf M, Verheyen K (2019b) Drivers of aboveground understorey biomass and nutrient stocks in temperate deciduous forests. J Ecol. https://doi.org/10.1111/1365-2745.13318

McRoberts RE, Tomppo EO, Næsset E (2010) Advances and emerging issues in national forest inventories. Scand J Forest Res 25:368-381. https://doi.org/10. 1080/02827581.2010.496739

Melo LC, Schneider R, Fortin M (2018) Estimating model- and sampling-related uncertainty in large-area growth predictions. Ecol Model 390:62-69. https:// doi.org/10.1016/j.ecolmodel.2018.10.011

Muukkonen P, Mäkipää R (2006) Empirical biomass models of understorey vegetation in boreal forests according to stand and site attributes. Boreal Environ Res 11:355-369

Muukkonen P, Mäkipää R, Laiho R, Minkkinen $K$, Vasander $H$, Finér L (2006) Relationship between biomass and percentage cover in understorey vegetation of boreal coniferous forests. Silva Fenn 40:231-245

Schulze IM, Bolte A, Schmidt W, Eichhorn J (2009) Phytomass, litter and net primary production of herbaceous layer. In: Brumme R, Khanna P (eds) Functioning and Management of European Beech Ecosystems, Ecological Studies, vol 208. Springer, Berlin Heidelberg, pp 155-181. https://doi.org/10 1007/b82392_11

Shaver GR, Chapin FS (1991) Production: biomass relationships and element cycling in contrasting Arctic vegetation types. Ecol Monogr 61:1-31. https:// doi.org/10.2307/1942997

Thürig E, Kaufmann E (2010) Increasing carbon sinks through forest management: a model-based comparison for Switzerland with its eastern plateau and eastern Alps. Eur J Forest Res 129:563-572. https://doi.org/10. 1007/s10342-010-0354-7

Tomppo E, Gschwantner T, Lawrence M, McRoberts RE (eds) (2010) National forest inventories : pathways for common reporting. Springer, Heidelberg. https://doi.org/10.1007/978-90-481-3233-1

Venables WN, Ripley BD (2002) Modern Applied Statistics with S. Fourth Edition. Springer, New York.

Welch NT, Belmont JM, Randolph JC (2007) Summer ground layer biomass and nutrient contribution to above-ground litter in an Indiana temperate deciduous Forest. Am Midl Nat 157(11-26):16

\section{Submit your manuscript to a SpringerOpen ${ }^{\circ}$ journal and benefit from:}

- Convenient online submission

- Rigorous peer review

- Open access: articles freely available online

- High visibility within the field

- Retaining the copyright to your article

Submit your next manuscript at $\boldsymbol{\nabla}$ springeropen.com 